\title{
USING 80/20 PRINCIPLE TO IMPROVE DECISION MAKING AT PFMEA
}

\author{
Nikola Banduka, Ivan Mačužić, Željko Stojkić, Igor Bošnjak \& Ivan Peronja
}
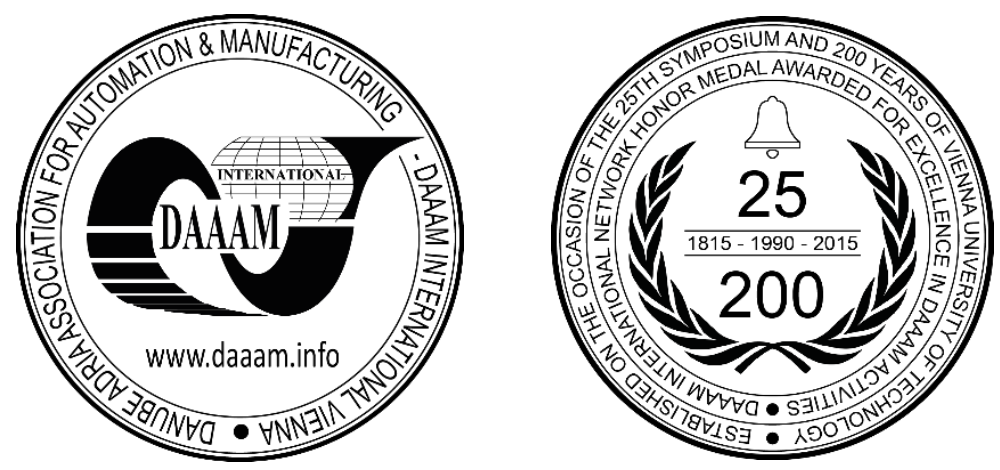

This Publication has to be referred as: Banduka, N[ikola]; Macuzic, I[van]; Stojkic, Z[eljko]; Bosnjak, I[gor] \& Peronja, I[van] (2016). Using 80/20 Principle to Improve Decision Making at PFMEA, Proceedings of the 27th DAAAM International Symposium, pp.0487-0492, B. Katalinic (Ed.), Published by DAAAM International, ISBN 978-3-90273408-2, ISSN 1726-9679, Vienna, Austria

DOI: $10.2507 / 27$ th.daaam.proceedings.073

\begin{abstract}
Turbulent market of today is forcing companies to respond on customer demands very fast, with right quality and acceptable price. Producing in quality is often hard and time-consuming job, with many risks. One of those risks can be defect (failure) appearance during the production process. One of quite often used analysis for this purpose is failure mode and effect analysis. This method is relatively accurate, but it is a very time-consuming method, and companies need to respond fast to customer demands with right quality. Another problem in this method is that all products and failures are ranked with the same value, which is an ideal case. However, more often case is that less percentage of products give most of the company profit. So, in this paper, the principle 80/20 (old Pareto principle) was used to help in decision making due to PFMEA realization.
\end{abstract}

Keywords: Production process; FMEA; PFMEA; Principle 80/20.

\section{Introduction}

Turbulent market of today is pressuring companies to respond on customer demands very fast, with right quality and acceptable price. These three factors (Time, quality, and price) are in an interaction and interdependence, so ideal balance between them should be found with the aim to achieve customer satisfactory [1]. Producing in quality is often hard and time-consuming job, with many risks. One of those risks can be defect (failure) appearance during production process. This problem can be controlled with various tools, techniques, and methods, and one very famous is Failure mode and effect analysis wider known as FMEA.

In general FMEA is a systematic method for identifying and preventing product and process problems before they occur [2]. FMEA can be used for specific needs, design, process, system, machine, service implementation phase, operations, maintenance, etc $[1,3]$. But the most often it is used for product design or production process. This types are also known as DFMEA and PFMEA. This paper is focused on PFMEA.

Modern PFMEA dates back to 1990s, when three leading American companies Chrysler LLC, Ford Motor Company, and General Motors Corporation forced all their suppliers to use PFMEA as preventing tool [1,2]. That created problems and confusion at suppliers. So Automotive industry agency group (AIAG) integrated different FMEA regulations in one unity and in 1993, a guide "Potential FMEA" was published ( $4^{\text {th }}$ edition from 2008 is active today) [4]. In short, these three companies made PFMEA famous and important. Since then PFMEA has been used in various industries and for 
different purposes. This method also has many shortcomings, and various authors have tried to improve it by modifying, or combining and integrating it with some other methods, but in practise it is still mostly used traditional approach to PFMEA.

Study conducted with 150 automotive companies shows that the highest number of surveyed companies see PFMEA as additional administrative work which wastes a lot of time, and gives back less benefits [5]. The biggest problem lays in this. It should be different, companies should use less time to get more benefits.

Solution might be found in philosophy of the 80/20 principle - the secret to achieving more with less [6]. 80/20 Principle is old Pareto's principle in modern era rehabilitated and improved by Richard Koh. Main idea of this principle is that $80 \%$ of total benefits can be achieved with $20 \%$ of total effort. And that is exactly what is needed for PFMEA. So, in this paper a combination of 80/20 Principle with PFMEA in a practical example is presented. The idea was to make a model which will calculate PFMEA indexes with additional coefficient achieved from 80/20 principle. The purpose of $80 / 20$ principle in this paper is segregation of products which give the highest percentage of total profit, and giving them higher priority. As result, a model with better risk priority index which facilitates decisions making at PFMEA was achieved.

\section{PFMEA}

PFMEA is a team based method, and for this purpose, a classical brainstorming technique is usually used. It is deductive type of method with structural top-down approach $[1,7,8]$. Failure problems should be solved according to the highest priority defined with Risk priority number index (RPN). Traditional RPN is calculated by multiplication of S (Severity), O (occurrence) and D (detection) index (see equation 1). And corrections should be done mandatory if RPN exceeds 100 , or if one of S, O, or D indexes has 9 or 10 value of failure.

First FMEA was founded for the USA military needs under the name "Military procedure MIL-P-1629" [9]. The Principle that was used at that time for FMEA report fulfilment as well as concept of that analysis is not in use anymore. First formal use of FMEA analysis was in aerospace industry.

Today FMEA is in wide use all over the world and it has become standard practice in Asian, American, and European companies [10]. The most common practice of use of FMEA is in automotive and aerospace industry, and in addition to this it is also used in military industry, industry for manufacturing of electrical components, nuclear industry, and in medicine [1, 7-14]. Addition to this, there is also use of FMEA in retail manufacturing, power plants, construction, telecommunication, mechanical and service industry, companies for computer systems embedding, companies for hardware and software making, information systems, food production companies, plastic injection companies, etc. [1, 2, 8-10, 14-19].

$$
R P N=\mathrm{S} * 0 * \mathrm{D}
$$

\section{3. $80 / 20$ Principle}

80/20 Principle is showing how more benefits can be achieved with less investment (see fig. 1). But this does not mean that proportion must be $80 / 20$. In most of cases it is, but not in all. The number even does not need to have 100 in sum.

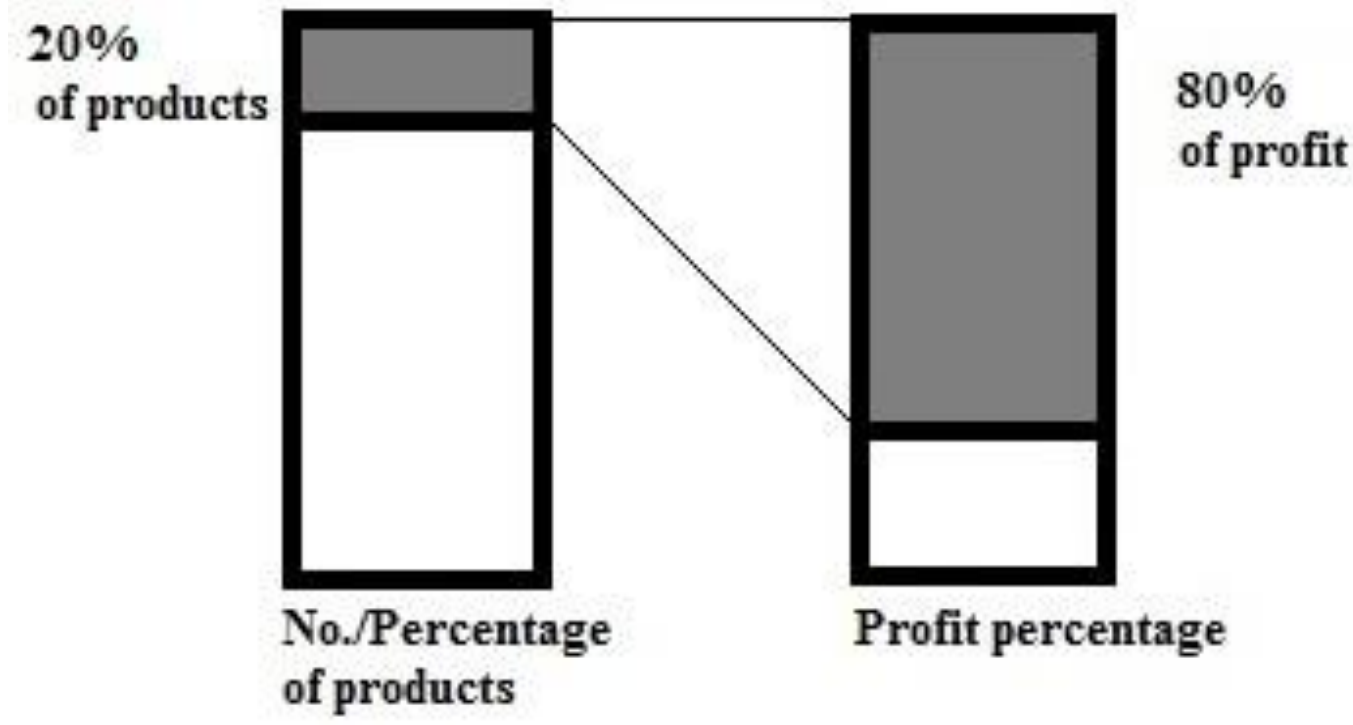

Fig. 1. The ratio of $80 / 20$ principle [6]. 
The precursor to 80/20 principle was discovered by Italian economist Vilfredo Pareto in 1897 [6]. From that time this principle has had a lot of names, and some of them are: the Pareto principle, the Pareto rule, the rule 80/20, etc. After Pareto's death this principle was forgotten until World War II. Many years later Harvard philology professor Zipf, G. K. [20] started to use Pareto rule again and he named it "Principle of least effort". It is evident that this researcher, among other fields, applied this principle in industry. Another and maybe even more important scientist for this kind of research interests, Juran, J. M. [21] also used this principle just two years later. Juran was responsible for quality revolution from 1950s to 1990s. Opposite to Zipf, Juran was employed in industry as industrial engineer. He used 80/20 principle as a principle for quality improvement, and called it "rule of important minority".

Today, this principle is very often used in everyday life. So it can be used by any intelligent person, organization, social group, company, etc. It is evident that 80/20 principle has brought great discoveries in business and economy. But, it also brought many benefits to various companies such as IBM, Apple, Lotus, Microsoft, etc [6].

\section{Using 80/20 principle to improve PFMEA decision making}

There are two known applications of Pareto and FMEA which are similar to this approach, but very different in purpose and structure [1, 22, 23]. The idea of using 80/20 principle to improve PFMEA is in focusing on failures which occur at products which are more valuable for company than others. During PFMEA realization, a team is looking on products and failures as they are all the same, and priority are those with the highest RPN coefficient. That is an ideal case. But in practise, it is usually different. Value of failure also depends on product value, and the product value depends on the amount of contribution or profit which it brings to a company. So, in ranking of RPN, value of the products should be included.

Why is this so important? In industry, it is not so simple to invest in everything that is needed. Top management is usually focused on direct return from investments. When failure is occurring, it is normally to made prevention and correction which is time-consuming and requires some additional costs. So, 80/20 principle should point out in which process and failures it is more profitable to invest, and which are less important according to product profitability priority. For this purpose, a coefficient $\mathrm{K}_{\mathrm{VP}}$ is invented which is included in traditional RPN (see equation 2).

$\mathrm{K}_{\mathrm{VP}}$ is coefficient of product value, defined by $80 / 20$ principle. $\mathrm{K}_{\mathrm{VP}}$ may have two numerical values (1 or 2 ). Less percentage of total products which gives bigger amount of profit gets value 2, while higher percentage which gives less percentage of profit gets value 1 . The principle of $\mathrm{K}_{\mathrm{VP}}$ defining will be shown in the next chapter in a practical example.

$$
R P N=\mathrm{S} * \mathrm{O} * \mathrm{D} * \mathrm{~K}_{V P}
$$

\section{Example}

In order to show improvements and difference between traditional PFMEA and improved PFMEA approach with using of 80/20 principle, 10 different arbitrary failures which respectively occurs on 10 different products were taken. Traditional PFMEA calculation is shown in Table 1.

The highest priority of this 10 failures was defined by classical RPN index. Failures were classified in table 1 according to highest value of RPN respectively from the highest to the lowest. So failures calculated on traditional way are ready for comparation.

\begin{tabular}{|c|c|c|c|c|c|}
\hline Failure & S & O & D & RPN & $\begin{array}{c}\text { The highest } \\
\text { priority }\end{array}$ \\
\hline F1 & 6 & 4 & 3 & 72 & F8 \\
\hline F2 & 3 & 7 & 4 & 84 & F10 \\
\hline F3 & 5 & 5 & 2 & 50 & F2 \\
\hline F4 & 3 & 2 & 3 & 18 & F9 \\
\hline F5 & 2 & 8 & 1 & 16 & F1 \\
\hline F6 & 3 & 5 & 2 & 30 & F3 \\
\hline F7 & 5 & 3 & 8 & 40 & F7 \\
\hline F8 & 7 & 6 & 5 & 210 & F6 \\
\hline F9 & 4 & 4 & 5 & 80 & F4 \\
\hline F10 & 6 & 3 & 7 & 126 & F5 \\
\hline
\end{tabular}

Table 1. Example of traditional PFMEA calculation.

Now is shown an example of improved PFMEA with application of 80/20 principle, with $\mathrm{K}_{\mathrm{VP}}$ coefficient influence included. Table 2 shows 10 arbitrary used products (with profit data included) which contribute to a company. Software extension for MS Excel - QI Macros 2016 [24] was used for 80/20 principle calculation. In this case all failures belongs to different products respectively. But in some other cases it is possible to have more than one failures for one product. 80/20 chart (see Fig. 2) is based on products on one side and profit data on the other side from Table 2. 


\begin{tabular}{|c|c|c|}
\hline Product & Profit (€) & Profit [\%] \\
\hline P1 & 5780 & 1.307 \\
\hline P2 & 32400 & 7.328 \\
\hline P3 & 37000 & 8.369 \\
\hline P4 & 20000 & 4.524 \\
\hline P5 & 6950 & 1.572 \\
\hline P6 & 13600 & 3.076 \\
\hline P7 & 68900 & 15.584 \\
\hline P8 & 160000 & 36.188 \\
\hline P9 & 19000 & 4.297 \\
\hline P10 & 78500 & 17.755 \\
\hline Total & 442130 & 100 \\
\hline
\end{tabular}

Table 2. Data needed for application of $80 / 20$ principle in determining $K_{V P}$.

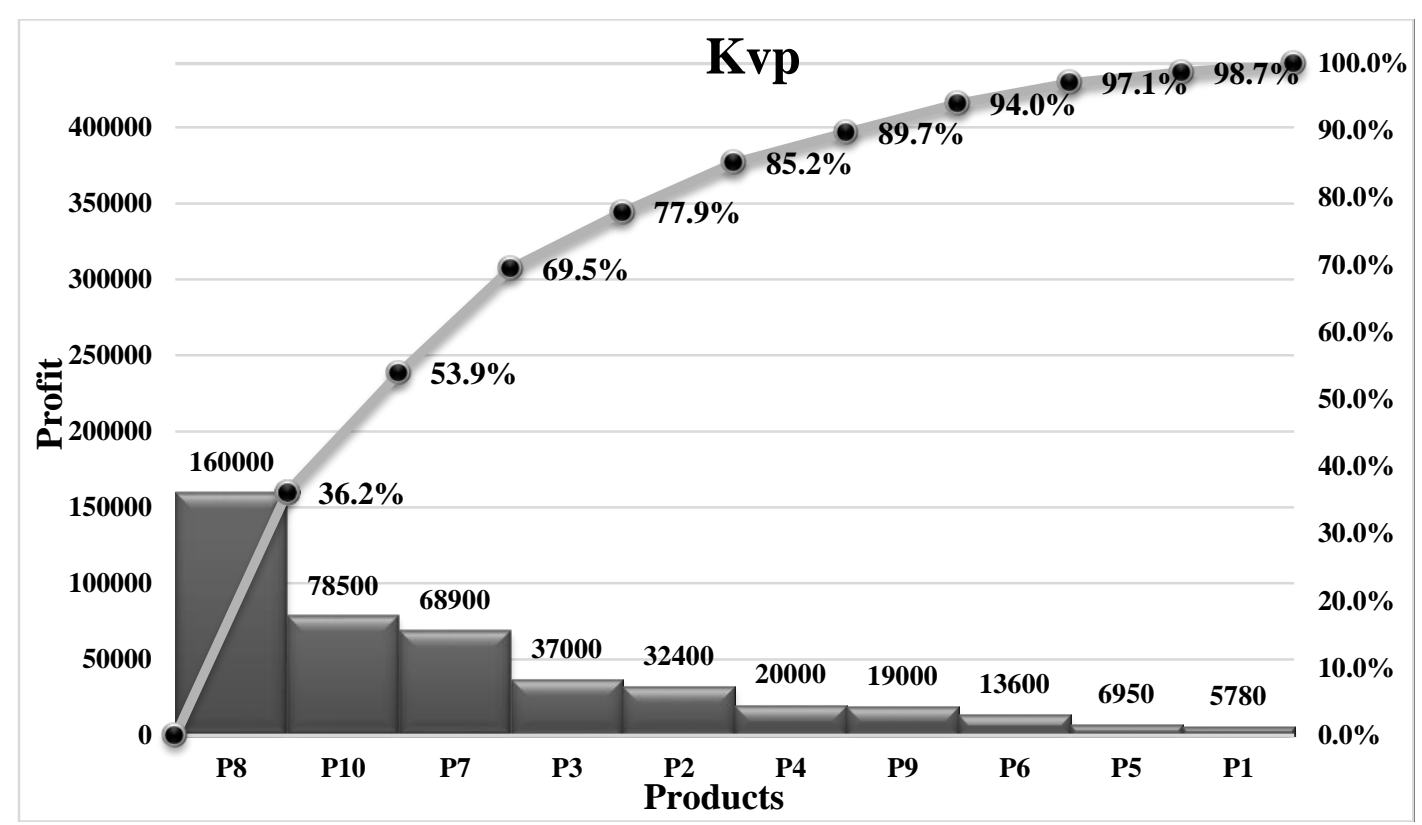

Fig. 2. Using QI Macros 2016 for Defining of $\mathrm{K}_{\mathrm{VP}}$ coefficient.

As it can be seen in the chart, almost $70 \%$ of total profit of the company is achieved from $30 \%$ of total products. Therefore, in this case, 70/30 principle is active. Value 2 for $\mathrm{K}_{\mathrm{VP}}$ coefficient is assigned to products with $30 \%$ ( $\mathrm{P} 8, \mathrm{P} 10$, and P7) of less, and for the other products (P3, P2, P4, P9, P6, P5, and P1) of more the value of $\mathrm{K}_{\mathrm{vP}}$ is 1.

After defining $\mathrm{K}_{\mathrm{VP}}$ coefficient, everything needed for a new approach calculation is ready. Table 3 shows calculation of new RPN with $\mathrm{K}_{\mathrm{VP}}$ coefficient included.

\begin{tabular}{|c|c|c|c|c|c|c|}
\hline Failure & S & O & D & KVP $_{\text { }}$ & RPN & The highest priority \\
\hline F1 & 6 & 4 & 3 & 2 & 144 & F8 \\
\hline F2 & 3 & 7 & 4 & 1 & 168 & F3 \\
\hline F3 & 5 & 5 & 2 & 2 & 200 & F2 \\
\hline F4 & 3 & 2 & 3 & 1 & 18 & F1 \\
\hline F5 & 2 & 8 & 1 & 1 & 36 & F10 \\
\hline F6 & 3 & 5 & 2 & 1 & 60 & F9 \\
\hline F7 & 5 & 1 & 8 & 1 & 40 & F6 \\
\hline F8 & 7 & 6 & 5 & 2 & 840 & F7 \\
\hline F9 & 4 & 4 & 5 & 1 & 80 & F5 \\
\hline F10 & 6 & 3 & 7 & 1 & 126 & F4 \\
\hline
\end{tabular}

Table 3. Calculation of RPN with $\mathrm{K}_{\mathrm{VP}}$ coefficient included.

Achieved results (see Table 1 and Table 3) show that a new approach sets a priority to the failures different from traditional approach. The difference is seen in 8 failures, while two are in the same place of priority. So this improved method shows that it is more efficient then traditional method. 


\section{Conclusion}

In this paper a new approach with new coefficient included $\left(\mathrm{K}_{\mathrm{VP}}\right)$ is shown which is defining products priority. One of very important things to deffine is which products mostly contribute to the company. In PFMEA all products are the same, as failures. Failures priorities are defined according to the highest RPN number, so importance of products is neglected. In this paper, 80/20 Principle helped in defining the highest priority products, which mostly contribute to the company. This combination of approaches proved bigger accuracy and it is easy for use.

One of shortcomings in this new approach might be separation of failures. Because this approach requires centralized base of failures. But it depends on a point of view. If it is observed from the side of time and cost it is an advantage, because it saves a lot of time and it is oriented to products which contribute the most to the company. But if it is observed from the side of company which wants to solve all problems and have time for all of it, then it can be complicated for use, because this method is primarily decision making oriented. Also, possible solution is that all products give the same value or 50/50 ratio, but that is rare or ideal case.

Future research should be cost oriented failure, because that is one more factor which influences PFMEA, but in combination with a new approach. And it is highly recommended to use it in combination with product priority coefficient KVP.

\section{Acknowledgments}

This work has been fully supported by Croatian Science Foundation under the project Innovative Smart Enterprise INSENT (1353).

\section{References}

[1] Stamatis, D. H. (2003). Failure mode and effect analysis: FMEA from theory to execution. ASQ Quality Press.

[2] Mikulak, R. J., McDermott, R., \& Beauregard, M. (2008). The basics of FMEA. CRC Press.

[3] Liu, H. C. (2016). FMEA Using Uncertainty Theories and MCDM Methods. Springer, Singapore.

[4] Chrysler LLC, Ford Motor Company, General Motors Corporation (2008). POTENTIAL FAILURE MODE AND EFFECT ANALYSIS (FMEA), Available from www.engmatl.com/home/finish/20-engineering.../160-fmeamanual, Accessed: 2016-08-29

[5] Johnson, K. G., \& Khan, M. K. (2003). A study into the use of the process failure mode and effects analysis (PFMEA) in the automotive industry in the UK. Journal of Materials Processing Technology, Vol.139., No.1., August 2003, pp.348-356, ISSN: 0924-0136

[6] Koch, R. (1999). The 80/20 principle: the secret to achieving more with less, Crown Business, ISBN:0385491743, Available from http://leadershipcoachingblog.com/wp-content/uploads/2012/03/the-80-20-principle-to-achievemore-with-less-effort1.pdf, Accessed: 2016-08-29

[7] Singh, V., Pungotra, H., Singh, S., \& Gill, S. S. (2013). Prioritization of Failure Modes in Process FMEA using Fuzzy Logic. International Journal Of Enhanced Research In Science Technology \& Engineering, Vol. 2, No.2, February 2013, ISSN: 2319-7463

[8] Dinmohammadi, F., \& Shafiee, M. (2013). A fuzzy-FMEA risk assessment approach for offshore wind turbines. International Journal of Prognostics and Health Management, Vol. 4, No.13, pp.59-68, 2013, ISSN:21532648

[9] Santos, F. R. S. D., \& Cabral, S. (2008). FMEA and PMBOK applied to project risk management. JISTEM-Journal of Information Systems and Technology Management, Vol.5, No.2, 347-364, 2008, ISSN:1807-1775

[10] Pentti, H., \& Atte, H. (2002). Failure mode and effects analysis of software-based automation systems, STUK Radiation and Nuclear Safety Authority. Helsinki: August 2002, p.37. Available at http://www.fmeainfocentre.com/handbooks/softwarefmea.pdf, accessed June 13, 2016.

[11] Breiing, A. J., \& Kunz, A. M. (2002). Critical Consideration and Improvement of the FMEA, Proceedings of the TMCE, May 7 -11, 2012,Karlsruhe, Germany, pp. 519-530

[12] Arabian-Hoseynabadi, H., Oraee, H., \& Tavner, P. J. (2010). Failure modes and effects analysis (FMEA) for wind turbines. International Journal of Electrical Power \& Energy Systems, Vol. 32, No.7, pp.817-824., 2010, ISSN: 0142-0615

[13] Guimarães, A. C. F., \& Lapa, C. M. F. (2007). Fuzzy inference to risk assessment on nuclear engineering systems. Applied Soft Computing, Vol. 7, No.1, pp.17-28., 2007, ISSN: 1568-4946

[14] Deng, W. J., Chiu, C. C., \& Tsai, C. H. (2007). The Failure Mode and Effects Analysis Implementation for Laser Marking Process Improvement: A Case Study. Asian Journal on Quality, Vol. 8, No. 1, pp.137-153, 2007, ISSN: $1598-2688$ 
[15] Khasha, R., Sepehri, M. M., \& Khatibi, T. (2013). A Fuzzy FMEA Approach to Prioritizing Surgical Cancellation Factors. International Journal of Hospital Research, Vol.2, No.1, pp.17-24, 2013, ISSN:2322-2085

[16] Reiling, J. G., Knutzen, B. L., \& Stoecklein, M. (2003). FMEA-the cure for medical errors. Quality progress, Vol. 36, No. 8, pp.67, 2003, ISSN:0033524X

[17] Stålhane, T., \& Wedde, K. J. (1997). Modification of safety critical systems: an assessment of three approaches. In: Reliability, Quality and Safety of Software-Intensive Systems, pp.134-147, Springer US, ISBN: 978-0-41280280-5

[18] Goddard, P. L. (2000). Software FMEA techniques Proceedings of Reliability and Maintainability Symposium, February 2000, Los Angeles, California USA, ISSN:0149-144X ISBN: 0-7803-5849-X, pp.118-123, IEEE

[19] Scipioni, A., Saccarola, G., Centazzo, A., \& Arena, F. (2002). FMEA methodology design, implementation and integration with HACCP system in a food company. Food control, Vol. 13, No. 8, pp.495-501, 2002

[20] Zipf, G. K. (1950). Human Behaviour and the Principle of Least Effort. The Economic Journal, Vol. 60, No. 240, pp. 808-810, December 1950, ISSN: 00130133

[21] Juran, J. M. (1954). Universals in management planning and controlling.Management Review, Vol. 43, No. 11., pp.748-761, 1954

[22] Zasadzień, M. (2014). Using the Pareto diagram and FMEA (Failure Mode and Effects Analysis) to identify key defects in a product. Management Systems in Production Engineering, Vol. 4, No. 16, pp.153-156, 2014, ISSN: 2299-0461

[23] Arvanitoyannis, I. S., \& Varzakas, T. H. (2007). Application of failure mode and effect analysis (FMEA), cause and effect analysis and Pareto diagram in conjunction with HACCP to a potato chips manufacturing plant. International journal of food science \& technology, Vol. 42, No. 12, pp.1424-1442, 2007, SSN: 0022-1155

[24] https://www.qimacros.com/, (2016). QI Macros 2016, KnowWare International, Inc., Denver, CO 80222 USA, Accessed on: 2016-08-29 